\title{
EDITORIALS
}

\section{The importance of primary care research in the management of respiratory disease}

\author{
See linked article by Pinnock et al. on pg 19
}

\section{*Stephen T Holgate ${ }^{\mathrm{a}}$ \\ a MRC Clinical Professor of Immunopharmacology and Chair of the UK Respiratory Research Collaborative, Southampton, UK}

*Correspondence: Professor Stephen T Holgate, Experimental Clinical Sciences, Sir Henry Wellcome Laboratory, Level F, Southampton General Hospital, Southampton, SO16 6YD, UK. Tel: +44 (0)2380796960 Fax: +44 (0)2380 701771

E-mail: sth@soton.ac.uk

Diseases involving the respiratory tract affect all age groups. They are not only very common but they carry high morbidity and in some cases death, thus leading to high health care utilisation.' The great difficulty with these diseases is that appreciable lung pathology can occur before symptoms become apparent or before patients are sufficiently aware of their significance - good examples being lung cancer and COPD, where delayed diagnosis has disastrous consequences. ${ }^{2}$ Unlike other organs the lung has few pain receptors except in the pleurae and oropharynx; symptoms manifest as cough, sputum production and shortness of breath. Lung disease has strong links to tobacco smoking, air pollution, industrial exposure and socioeconomic deprivation. Therefore, unlike diseases afflicting other organs such as the heart, endocrine system and central nervous system, respiratory disease has not attracted the attention it deserves. ${ }^{3}$ Such neglect has been strengthened by the stigmata that not infrequently accompany smoking-related lung disease or asthma. ${ }^{4,5}$

These complex perceptions operate in most countries and have contributed to the relatively poor progress made in preventing or curing respiratory diseases. However, the World Health Organization (WHO) now recognises that within a few years lung disease, and in particular COPD, will be the third most common cause of death worldwide by 2020, much of it tobacco-related or caused by infection. ${ }^{6}$ The recent viral pandemics involving coronovirus causing SARS, and the influenza H5N1 (avian) and H1N1 (swine) outbreaks, illustrate how potentially devastating mutations in microorganisms with which we are familiar - coronovirus usually causes common colds - can be.? The acquisition of anti-microbial resistance is an added problem in viral pandemics, nosocomial and community acquired pneumonia, and tuberculosis.,9

Diseases of the upper respiratory tract are also underestimated in their impact, especially rhinitis and rhinosinusitis. ${ }^{10}$ Such disorders are often trivialised without us realising their impact on performance and quality of life. Most upper respiratory diseases also coexist with lung disease (especially asthma and COPD) and yet these are rarely considered together when clinical presentation occurs through either the lower or upper respiratory tracts." Finally, there are the less common respiratory diseases that can masquerade as other diseases such as asthma in the beginning, but which turn out to be sleep apnoea, vocal cord dysfunction, autoimmune and eosinophilic lung disease, sarcoidosis, interstitial pulmonary fibrosis or idiopathic pulmonary hypertension. ${ }^{12}$

Another important facet of most lung disorders is the heterogeneity that exists in response to individual treatments. The drive towards evidenced-based practice has led to a proliferation of management guidelines with little involvement of those expected to deliver the guideline recommendations. The majority of guidelines rely on randomised control trials to provide the necessary evidence, but these are often conducted in highly selected patient populations that are far from representative of those expected to receive the specific treatment. ${ }^{13}$ One example of this is asthma, where less than $4 \%$ of the total eligible asthma disease population is eventually included in trials of asthma drugs. These trials then assume that all patients will respond in a similar manner. ${ }^{14,15}$ However, this is simply not true. A good example is the failure of inhaled corticosteroid (ICS) treatment in patients with asthma who smoke, whereas leukotriene receptor antagonists (LTRAs) maintain their efficacy. ${ }^{16}$ Put simply, within complex lung disease there are multiple phenotypes involving different causal pathways. The concept of the responder and nonresponder to a therapy is now well accepted even when attention is being paid to treatment adherence. As a speciality, medicine is now moving towards a stratified approach using pathway-specific diagnostic tests to select the most appropriate treatment tailored to a patient's need. ${ }^{17}$ Cancer diagnostics are leading the field, but treatments for chronic inflammatory diseases are close behind. ${ }^{18}$

Aside from the pathophysiological reasons for explaining treatment variation, adherence to prescribed treatment is a crucial factor. This is especially so with inhaled drugs which are used to control diseases such as asthma and rhinitis, despite every attempt by health practitioners and pharmacists to teach patients good practice and explain to them the importance of continuing therapy even though they may be free of current symptoms. Guidelines widely state that ICS are superior to LTRAs in the first line treatment of adult asthma, but a recent pragmatic "real world" trial in primary care using patient-related outcome measures as well as lung function failed to 
show any difference between the two treatments. ${ }^{19}$ Similar findings were reported when comparing an inhaled long-acting $\beta_{2}$-agonist (LABA) (supposedly the superior treatment in efficacy studies) with an LTRA as add-on therapy in more severe asthma uncontrolled with moderate-high dose ICS. ${ }^{19}$ As might be predicted, there was an enormous debate on the validity of such pragmatic studies when placebo as a comparator was omitted. ${ }^{20-22}$ However, this debate somewhat misses the point; what is the purpose of prescribing drugs to a population if they either do not work (on account of disease heterogeneity) or there are compliance issues (i.e. whether or not the patient is taking the drug on a regular basis as prescribed)?

Since the majority of lung disease is managed in primary care, the issues outlined above have a strong influence on practice, disease prevention and control, quality of life and patient satisfaction. ${ }^{23}$ But how does one develop an evidence base to guide practice in primary care in a group of diseases that represent a high proportion of clinical practice? There have been several recent attempts to derive research priorities in respiratory disease with some success in helping to increase and redirect research funding. Most of these have relied upon expert panels selecting priorities from surveys of health professionals, scientists and occasionally patients ${ }^{24,25}$ - such as that involving Asthma UK and the British Thoracic Society by the James Lind Alliance (http://www.lindalliance.org/Asthma_Working_Partnership.asp). In the UK, the formation of a multi-professional Respiratory Research Collaborative (UKRRC, http://www.brit-thoracic.org.uk/researchinnovation/ukrrc.aspx) ${ }^{26}$ comprising professional societies, scientists, the lung-related charities, the Medical Research Council (MRC), the Department of Health, and industry, have identified research priorities identified through a Delphi process ${ }^{27}$ that were then picked up by the research community. This resulted in a 3 -fold increase in grants, studentship and fellowship awards over the three years since its launch - and this has been maintained (see Figure 1). This remarkable turnaround came about as much through the respiratory research community recognising that they needed to join forces with each other for maximum effect and the subsequent formation of

\section{Figure 1. MRC respiratory spend 2004/5 to 2010/11}

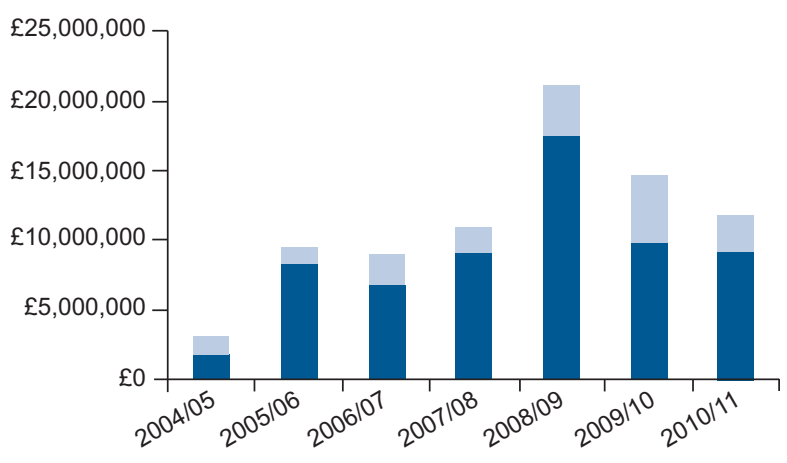

Value of Fellowships awarded

Value of Grants awarded national research networks. ${ }^{28}$

In this issue of the Primary Care Respiratory Journal, Hilary Pinnock and members of the International Primary Care Respiratory Group (IPCRG) report the results of a comprehensive e-Delphi exercise to prioritise the respiratory research needs of primary care, ${ }^{29}$ which provides a most valuable response to international calls for action to prevent and treat non-communicable diseases that are rising at an alarming rate across the world in response to changing lifestyles. ${ }^{30}$ Respiratory disease is high on the agenda. The IPCRG began by publishing a research needs statement (RSN) involving participation of 22 countries with a range of socioeconomic backgrounds, from which were identified 145 research questions. ${ }^{31}$ Using three rounds of eDelphi, and using criteria of clinical importance, feasibility, and international relevance, these were refined down to seven research questions which achieved total agreement and 24 which reached the consensus threshold of $90 \%$. The thoroughness with which this survey was undertaken is to be admired, and as a result the conclusions have real meaning which demands action.

High on the priorities list was a need for evidence on how a diagnosis of a respiratory disease can be suspected in a consultation, and known respiratory conditions being assessed using "simple" tools. ${ }^{29}$ This clearly resonates with an urgent need for earlier diagnosis of respiratory disease and the need for tools which can easily follow the progress of disease over time. There was also emphasis on a need for real world studies conducted in primary care. Other notable themes were self management, step-up and step-down treatment regimes for asthma, treatment adherence, diagnosis and management of co-morbidities, early diagnosis and prevention of progression, educational needs of professionals, and combination therapy. It is important to recognise that just because a subject did not reach the top priority list it is not important or worthwhile. The methodology has led to overall priorities for research across national boundaries. However, many of the topics not making it into the final selection are of great relevance to specific countries or urban/rural differences in practice. The strength of the recommended topics will be highly influenced by those participating, and the authors acknowledge this and the potential distortions that this may introduce.

This thorough assessment of research needs in primary care ${ }^{29}$ is of enormous significance and is to be highly commended. What is now needed is to turn these priorities into research questions and grant proposals and, of course, for funding to follow. The only way this will occur is for the respiratory research community to join forces with this in mind and to move the exciting challenge provided by this gamechanging exercise into high quality research proposals, capacity building, new evidence and subsequent benefit to patients. We now all need to take individual and joint responsibility for this grand challenge.

Acknowledgements The author is an MRC Clinical Professor of Immunopharmacology.

Conflicts of interest The author is Chair of the UK Respiratory Research Collaborative.

Commissioned article; not externally peer-reviewed; accepted 17th January 2012; online 20th February 2012 
(C) 2012 Primary Care Respiratory Society UK. All rights reserved http://dx.doi.org/10.4104/pcri.2012.00015

Prim Care Respir J 2012; 21(1): 1-3

\section{References}

1. Worth A, Pinnock H, Fletcher M, Hoskins G, Levy ML, Sheikh A. Systems for the management of respiratory disease in primary care--an international series: United Kingdom. Prim Care Respir J 2011;20(1):23-32. http://dx.doi.org/10.4104 pcrj.2010.00070

2. Diaconescu R, Lafond C, Whittom R. Treatment delays in non-small cell lung cancer and their prognostic implications. J Thorac Oncol 2011;6(7):1254-9. http://dx.doi.org/10.1097/JTO.0b013e318217b623

3. Decramer M, Sibille Y. European conference on chronic respiratory disease. Lancet. 2011;377(9760):104-06. http://dx.doi.org/10.1016/S0140-6736(10)62239-8

4. McGrady ME, Cotton S, Rosenthal SL, Roberts YH, Britto M, Yi MS. Anxiety and asthma symptoms in urban adolescents with asthma: the mediating role of illness perceptions. J Clin Psychol Med Settings 2010;17(4):349-56. http://dx.doi.org/10.1007/s10880-010-9214-3

5. Halding AG, Heggdal K, Wahl A. Experiences of self-blame and stigmatisation for self-infliction among individuals living with COPD. Scand J Caring Sci 2011;25(1): 100-07. http://dx.doi.org/10.1111/j.1471-6712.2010.00796.x

6. Stuckler D. Population causes and consequences of leading chronic diseases: a comparative analysis of prevailing explanations. Milbank Q 2008;86(2):273-326. http://dx.doi.org/10.1111/j.1468-0009.2008.00522.x

7. Morens DM, Taubenberger JK, Harvey HA, Memoli MJ. The 1918 influenza pandemic: lessons for 2009 and the future. Crit Care Med 2010;38(4 Suppl):e1020. http://dx.doi.org/10.1097/CCM.0b013e3181ceb25b

8. Hong SD, Park SH, Kang SJ, et al. First Fatal Oseltamivir-Resistant 2009 Pandemic Influenza A (H1N1) Case in an Adult in Korea. Chonnam Med J 2011;47(2):127-9. http://dx.doi.org/10.4068/cmj.2011.47.2.127

9. van der Werf MJ, Langendam MW, Huitric E, Manissero D. Multidrug resistance after inappropriate tuberculosis treatment: A meta-analysis. Eur Respir J 2011 Oct 20. [Epub ahead of print].

10. Civelek E, Yavuz ST, Boz AB, et al. Epidemiology and burden of rhinitis and rhinoconjunctivitis in 9- to 11-year-old children. Am J Rhinol Allergy 2010;24(5): 364-70. http://dx.doi.org/10.2500/ajra.2010.24.3484

11. Boulet LP, Boulay MÈ. Asthma-related comorbidities. Expert Rev Respir Med 2011; 5(3):377-93. http://dx.doi.org/10.1586/ers.11.34

12. King CS, Moores LK. Clinical asthma syndromes and important asthma mimics. Respir Care 2008;53(5):568-80.

13. Price $D$, Thomas $M$. Breaking new ground: challenging existing asthma guidelines. BMC Pulm Med 2006;6(Suppl 1):S6. http://dx.doi.org/10.1186/1471-2466-6-S1-S6

14. Travers J, Marsh S, Williams M, et al. External validity of randomised controlled trials in asthma: to whom do the results of the trials apply? Thorax 2007;62(3):219-23. http://dx.doi.org/10.1136/thx.2006.066837

15. Jones R, Jones RO, McCowan C, Montgomery AA, Fahey T. The external validity of published randomized controlled trials in primary care. BMC Fam Pract 2009;10:5. http://dx.doi.org/10.1186/1471-2296-10-5

16. Lazarus SC, Chinchilli VM, Rollings NJ, et al. Smoking affects response to inhaled corticosteroids or leukotriene receptor antagonists in asthma. Am J Respir Crit Care Med 2007;175(8):783-90. http://dx.doi.org/10.1164/rccm.200511-17460C

17. Kirmani S, Babovic-Vuksanovic D. Towards individualized medicine: insights gained from genomic studies. Bosn J Basic Med Sci 2009;9(Suppl 1):11-16.

18. Maitland ML, Schilsky RL. Clinical trials in the era of personalized oncology. CA Cancer J Clin 2011;61(6):365-81. http://dx.doi.org/10.3322/caac.20135

19. Price $D$, Musgrave $S D$, Shepstone $L$ et al. Leukotriene antagonists as first-line or add-on asthma-controller therapy. N Engl J Med 2011;364(18):1695-707. http://dx.doi.org/10.1056/NEJMoa1010846

20. Dahlén SE, Dahlén B, Drazen JM. Asthma treatment guidelines meet the real world N Engl J Med 2011;364(18):1769-70. http://dx.doi.org/10.1056/NEJMe1100937

21. van Asperen PP. That ICS should be first line therapy for asthma--con. Paediatr Respir Rev 2011;12(4):250-2. http://dx.doi.org/10.1016/j.prrv.2011.05.008

22. Lands LC. Inhaled corticosteroids or leukotriene receptor antagonists as first line therapy for asthma: aspects to consider in the light of the pro-con debate. Paediatr Respir Rev 2011;12(4):243-4. http://dx.doi.org/10.1016/j.prrv.2011.05.010

23. Brazil K, Cloutier MM, Tennen $H$, Bailit $H$, Higgins PS. A qualitative study of the relationship between clinician attributes, organization, and patient characteristics on implementation of a disease management program. Dis Manag 2008;11(2): 129-37. http://dx.doi.org/10.1089/dis.2008.1120008

24. Chanez P, Wenzel SE, Anderson GP, et al. Severe asthma in adults: what are the important questions? J Allergy Clin Immunol 2007;119(6):1337-48. http://dx.doi.org/10.1016/j.jaci.2006.11.702

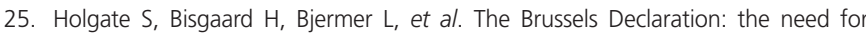
change in asthma management. Eur Respir J 2008;32(6):1433-42. http://dx.doi.org/10.1183/09031936.00053108

26. Holgate ST. Priorities for respiratory research in the UK. Thorax 2007;62(1):5-7 http://dx.doi.org/10.1136/thx.2006.073882

27. Sheikh A, Major P, Holgate ST. Developing consensus on national respiratory research priorities: key findings from the UK Respiratory Research Collaborative's eDelphi exercise. Respir Med 2008;102(8):1089-92. http://dx.doi.org/10.1016/j.rmed.2008.03.006

28. Holgate ST. The future of lung research in the UK. Thorax 2007;62(12):1028-32. http://dx.doi.org/10.1136/thx.2007.088971

29. Pinnock $H, \varnothing$ strem $A$, Rodríguez MR et al. Prioritising the respiratory research needs of primary care: the International Primary Care Respiratory Group (IPCRG) eDelphi exercise. Prim Care Respir J 2012;21:19-27. http://dx.doi.org/10.4104/pcrj.2012.00006

30. Mamudu HM, Yang JS, Novotny TE. UN resolution on the prevention and control of non-communicable diseases: an opportunity for global action. Glob Public Health 2011;6(4):347-53. http://dx.doi.org/10.1080/17441692.2011.574230

31. Pinnock $\mathrm{H}$, Thomas $\mathrm{M}$, Tsiligianni I et al. The International Primary Care Respiratory Group (IPCRG) Research Needs Statement 2010. Prim Care Respir J 2010;19(Suppl 1):S1-20 . http://dx.doi.org/10.4104/pcrj.2010.00021 